\section{Body window-enabled in vivo multicolor imaging of transplanted mouse islets expressing an insulin-Timer fusion protein}

\author{
Suzanne Bertera, Xuehui Geng, Zakaria Tawadrous, Rita Bottino, \\ A.N. Balamurugan, William A. Rudert, Peter Drain, Simon C. Watkins, \\ and Massimo Trucco \\ University of Pittsburgh, Pittsburgh, PA, USA
}

BioTechniques 35:718-722 (October 2003)

Type 1 diabetes results from the selective destruction of insulin-producing $\beta$ cells in the islets of Langerhans, and autoimmune T cells are thought to be the mediators of this destruction. $T$ cells are also responsible for allorejection once the islets are transplanted into a patient to reduce the negative consequences of a lack of insulin. To better understand these processes, we have developed a transgenic mouse expressing proinsulin II tagged with a live-cell fluorescent reporter protein, Timer. Timer protein is unique because it changes color from green to red in the first $24 \mathrm{~h}$ after synthesis. With this marker, insulin synthesis can be carefully monitored through fluorescent changes over time. To complement this new biotechnological research tool, we designed a body window to allow for in vivo imaging over time of the islets transplanted under the kidney capsule. The window device, which is sutured to replace the underlying skin and body wall over the site of islet transplantation, may be used to simultaneously observe $\beta$ cells and T cells that have been labeled with a fluorochrome distinguishable from Timer. The imaging of both insulin-producing cells and T cells may be carried out repeatedly for a week or more with no need for repeated surgery, while preserving the life of the studied animal.

\section{INTRODUCTION}

Autoimmune type 1 diabetes mellitus (T1DM) is a complex disease that still presents many puzzles relative to its etiology and possible therapies (1). Insulin-dependent diabetic patients have few options for treatment. While the most common therapy is daily multiple injections of insulin, one alternative that has most recently gained favor is the replacement of the islets of Langerhans by allotransplantation, following the Edmonton protocol (2). The insulin-producing cells (i.e., the $\beta$ cells) already lost at the time of the clinical onset of the disease can be replaced in this way. However, one of the major problems with islet transplantation is that two or three human donor organs are necessary to successfully treat one diabetic patient because of the damage these cells suffer during isolation (3). In addition, it is not known what happens to the islets immediately after transplantation or why and when they stop producing insulin; the percentage of patients who did not require exogenously admin- istered insulin in the Edmonton protocol, close to $80 \%$ the first year, seems to have reached the 50\% mark at the end of the second year (4).

To study insulin secretion in endogenous or transplanted islets, it would be helpful to have a visible signal that shows when insulin is being generated in live $\beta$ cells and how long it stays in the cells before being released after high glycemia is detected. With this concept in mind, we generated a transgenic mouse carrying pancreatic $\beta$ cells that fluorescently reveal not only when they are producing insulin but also how long it has been since they last synthesized it. This was accomplished by inserting the gene for the fluorescent Timer protein [developed by Terskikh et al. (5)] into the sequence encoding the C-peptide of murine insulin II to create Ins-C-Timer. Because the $\mathrm{C}$-peptide is normally cleaved when the $\mathrm{A}$ and $\mathrm{B}$ chains fold to generate the mature protein, the insulin molecule in the transgenic animal may still fold properly and the hormone may function physiologically (6). Fluorescent Timer is a mu- tated version of a red fluorescent protein obtained from the Anthozoa coral (7). These mutations permit its fluorescence to change from green when it is first synthesized to red over approximately $24 \mathrm{~h}$.

In this study, we combined the use of Ins-C-Timer with a body window device (Fotofab, Chicago, IL, USA) to allow for the imaging of insulin-producing cells over time and to directly determine their physiological as well as their pathological conditions. Direct imaging of the graft in vivo can be done without the need for repeated surgeries or sacrifice of the transplanted animal. The window device may also be used to image fluorescently labeled $\mathrm{T}$ cells, which is a feature that is extremely useful for monitoring allograft rejection of islets situated under the kidney capsule of the recipient mouse.

\section{MATERIALS AND METHODS}

\section{Generation of Ins-C-Timer Transgenic Mice}

The 2.4-kb BamHI genomic fragment of mouse insulin II (8) was inserted within an Xhol/HpaI fragment into the Adlox shuttle vector (9) to form Adlox.Insulin II. We made Timer based on the dsRed1 sequence by introducing the relevant mutations (5). The fluorescent Timer coding sequence was adapted using PCR to encode three flanking alanines at each end and sufficient C-peptide sequence to span between the SmaI and $B s t$ EII restriction sites. The insertion of the product into Adlox.Insulin II at these sites had the effect of replacing codon 20 (Ala) of C-peptide with the Ala-flanked Timer sequence. The accuracy of the Adlox.Ins-C-Timer construct was then confirmed by the DNA sequencing of the $\mathrm{XhoI} / \mathrm{HpaI}$ segment. Highly purified Adlox.Ins-C-Timer DNA was injected into fertilized embryos by the University of Cincinnati Transgenic Core (Cincinnati, OH, USA) to generate Ins-C-Timer transgenic founder mice.

The transgenic founders and offspring were identified by the PCR amplification of genomic DNA from each animal. Primer sequences were 5'-CCAGTTCCAGTACGGCTCCA-3' (forward primer) and $5^{\prime}$-TGGATCTCGCCCTTCAGCA-3' (reverse primer). 


\section{Islet and T Cell Preparation and Transplantation}

The mouse islets were isolated by collagenase digestion of the whole pancreas under sterile conditions and transplanted under the kidney capsule, following methods that have been previously described $(10,11)$.

For $\mathrm{T}$ cell preparation, spleen cells from animals syngeneic to the islet graft recipient were lysed of red blood cells by the addition of $2 \mathrm{~mL}$ Red Cell Lysing Reagent (Sigma, St. Louis, MO, USA)
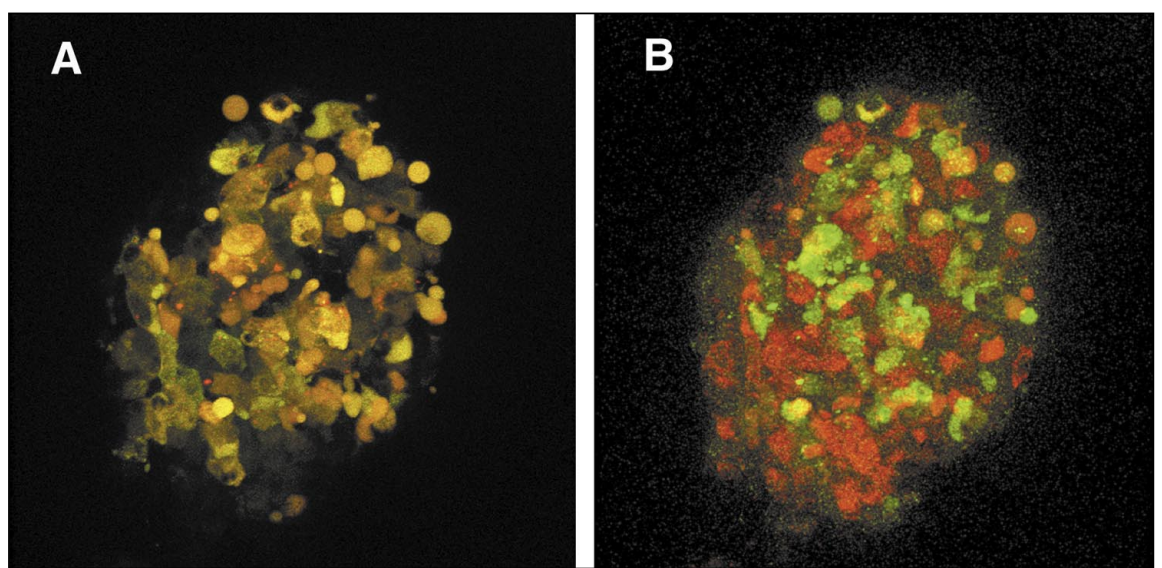

Figure 1. Ins-C-Timer islet exposure to interleukin 1 $\beta$. (A) Confocal micrograph of a normal Ins-CTimer islet isolated from the pancreas. The insulin is secreted as it is synthesized, and thus fluorescence does not build up in the $\beta$ cells, which look green and yellow. (B) The same islet after a 24 -h exposure to interleukin $1 \beta$ (IL-1 $1 \beta ; 50 \mathrm{U} / \mathrm{mL}$ ). Insulin secretion is inhibited by IL-1 $\beta$ so that the fluorescence in the $\beta$ cells is more abundant. As time passes after synthesis, more of the fluorescence converts from green to red. Original magnification was $40 \times$.

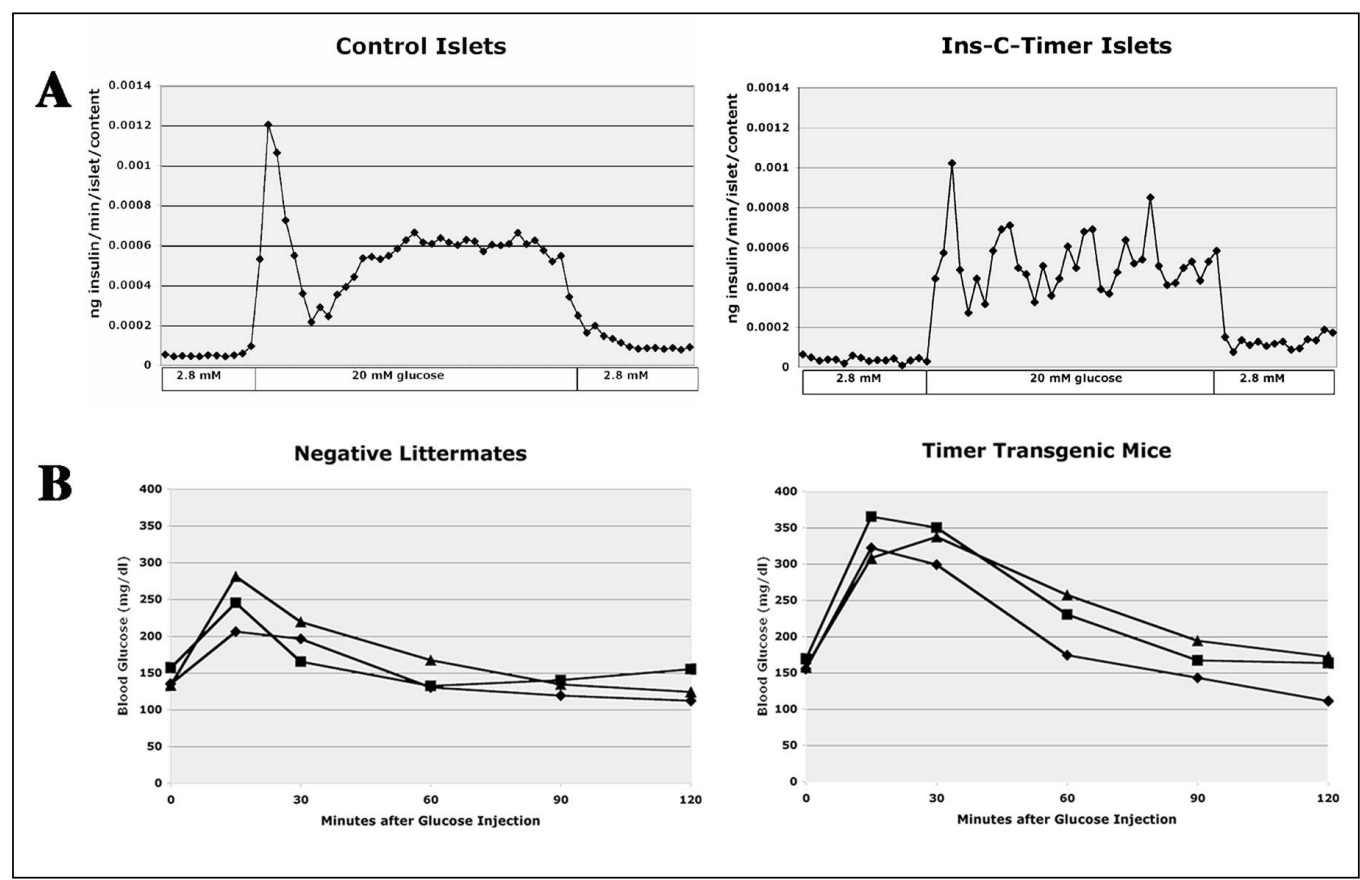

Figure 2. Insulin measurements in vitro and in vivo. (A) Insulin responsiveness to high glucose was measured by an in vitro perifusion assay. A 30-min low glucose $(2.8 \mathrm{mM})$ incubation was followed by the introduction of high glucose $(20$ $\mathrm{mM}$ ) for $30 \mathrm{~min}$, followed by low glucose. The insulin levels were measured by ELISA. The chart on the left shows the insulin-release profile of nontransgenic control islets, while the chart on the right is from Ins-C-Timer transgenic islets. (B) Insulin responsiveness to high glucose was measured in vivo by a intraperitoneal glucose tolerance test (IPGTT). Animals were fasted overnight and then given an introperitoneal injection of glucose $(100 \mathrm{mg} / \mathrm{mL})$ at $2 \mathrm{~g} / \mathrm{kg}$ body weight. Blood glucose was measured at time 0 (before injection), 15, 30, 60, 90, and $120 \mathrm{~min}$. The chart on the right shows the results of Ins-C-Timer mice from three different litters, and the chart on the left shows the corresponding littermates. for $2 \mathrm{~min}$. After washing, the cells were labeled with $5 \mu \mathrm{M}$ carboxyfluorescein diacetate succinimidyl ester (CFSE) (Molecular Probes, Eugene, OR, USA) for $15 \mathrm{~min}$ at $37^{\circ} \mathrm{C}$ and protected from light. CFSE is a long-lasting cellular dye with green fluorescence. The cells were washed, resuspended in phosphatebuffered saline (PBS), and injected intraperitoneally into recipient mice that had been transplanted with islets from nontransgenic littermates of the Ins-CTimer mice.

\section{The Body Window Device}

After islet transplantation, a 15-mm circular hole is excised from the outer skin and body wall through to the abdominal cavity at the level of the kidney. Any adipose tissue that is covering the kidney is cut away, and bleeding is cauterized. The window device is sutured into place with a single length of 5-0 Surgilene polypropylene cardiovascular suture (Davis \& Geck, Wayne, NJ, USA), taking care to make the final knot under the edge of the device. This is done to reduce the likelihood that the animal could bite at the sutures.

The device was manufactured from 1/16th inch stainless steel, based on our specifications. The ring-shaped device measures approximately 0.7 inches in diameter and has 16 smaller holes around the edges for suture attachment. Coverslip glass measuring $12 \mathrm{~mm}$ in diameter is used for the window and is attached to the metal with cyanoacrylate $(\mathrm{Su}$ per Glue ${ }^{\mathrm{TM}}$; Chemmer Enterprise, Taipei, Taiwan).

\section{Multicolor Two-Photon Microscopy}

Confocal images were collected using $488 \mathrm{~nm}$ excitation with a META 510 Confocal Microscope (Carl Zeiss, Thornwood, NY, USA) using spectral detection. Emission spectra between 490 and 570 
$\mathrm{nm}$ in 10-nm bands were collected for each image. Using the spectral unmixing capabilities of the instrument, spectra for the green component and red component of Timer were generated and used to unmix the aggregate spectral image. The two separated images were then recombined using green and red channels in a standard two-color image (12).

\section{RESULTS AND DISCUSSION}

Six Ins-C-Timer-positive founder mice were identified out of 50 pups born from injected embryos. Three of the founders did not transmit through the germline. Of the remaining three founders, the one with the best expression (no. 53,128) was bred to produce the Ins-C-Timer transgenic line described here. Figure 1A shows an example of isolated transgenic islets. With the addition of interleukin $1 \beta$ (IL-1 $\beta$ ), which is an inhibitor of insulin secretion, the $\beta$ cells fluoresce more in red (Figure 1B).

To assess the insulin-secretory capacity of islets from Ins-C-Timer and nontransgenic controls, we used a dynamic glucose challenge involving the perifusion of isolated islets with Krebs buffer under conditions of low and high glucose (13). The overall basal and stimulated insulin releases were similar between the control and Timer islets. A slight but insignificant lower insulin content was measured in Timer islets (Table 1). However, the perifusion curve indicates that after stimulation, the Timer islets showed fluctuating insulin release (Figure 2A). By a fasting intraperitoneal glucose tolerance test (IPGTT) (14), the Ins-C-Timer mice showed a higher initial glycemic response and a slight delay in recovery from the glucose challenge compared to nontransgenic mice (Figure 2B).

Although we have not yet clarified the cause of this phenomenon, the IPGTT results may be explained by the competition that takes place in the transgenic animals between the transgenic and endogenous insulin promoters for activating factors. This is particularly true if the transgene is present in the mouse line in a high copy number. The number of islets does not seem to be a factor because it is similar between

Table 1. In Vitro Functional Testing of Isolated Islets

\begin{tabular}{|lcccc|}
\hline & $\begin{array}{c}\text { Basal Insulin } \\
\text { Release } \\
\text { (ng/min/islet) }\end{array}$ & $\begin{array}{c}\text { Stimulated Insulin } \\
\text { Release } \\
\text { (ng/min/islet) }\end{array}$ & $\begin{array}{c}\text { Stimulation } \\
\text { Index }\end{array}$ & $\begin{array}{c}\text { Insulin } \\
\text { Content } \\
\text { (ng/islet) }\end{array}$ \\
\hline $\begin{array}{l}\text { Control } \\
(n=3-6)\end{array}$ & $0.0035 \pm 0.0009$ & $0.0170 \pm 0.0031$ & $5.31 \pm 0.94$ & $53.8 \pm 11.4$ \\
$\begin{array}{l}\text { Timer } \\
(n=5-7)\end{array}$ & $0.0029 \pm 0.0003$ & $0.0196 \pm 0.0009$ & $7.59 \pm 2.77$ & $39.9 \pm 8.2$ \\
$\begin{array}{l}\text { Data are means }(\bar{x} \pm \text { SEM). Basal and stimulated insulin releases are measured at } \\
2.8 \text { and 20 mM glucose concentrations. The stimulation index expresses the ratio } \\
\text { between stimulated and basal insulin releases. }\end{array}$ \\
\hline
\end{tabular}

transgenic and the nontransgenic littermates, as indirectly demonstrated by islet isolation yields (data not shown). Comparing transgenic animals generated with green fluorescent protein or Timer-labeled C-peptides, the latter seems to be less toxic for the cells of a developing embryo (S. Bertera, P. Drain, and $\mathrm{M}$. Trucco, unpublished data). However, this does not exclude the possibility that the fluorochrome-labeled proinsulin may be processed more slowly than the physiologic one or that the presence of the fluorochromeC-peptide fusion molecule in the secretory granules has an effect on the secretion of the hormone after a hyperglycemic stimulus.

We hoped to reduce these problems by generating new mice in which two copies of the gene for insulin II are replaced by knockin procedures with homologous sequences encoding the C-peptide marked with Timer. Once the double knockin mouse is generated, the stoichiometric ratio between Timer expression and insulin production should be 1:1, so that the expression of the fluorochrome reveals true proinsulin synthesis.
In mice, the islets are usually transplanted under the kidney capsule. Thus, the placement of the body window is simple because the incision made to expose the kidney and perform the transplant can be adapted to allow for the placement of the window device. After recovering from anesthesia, the mouse

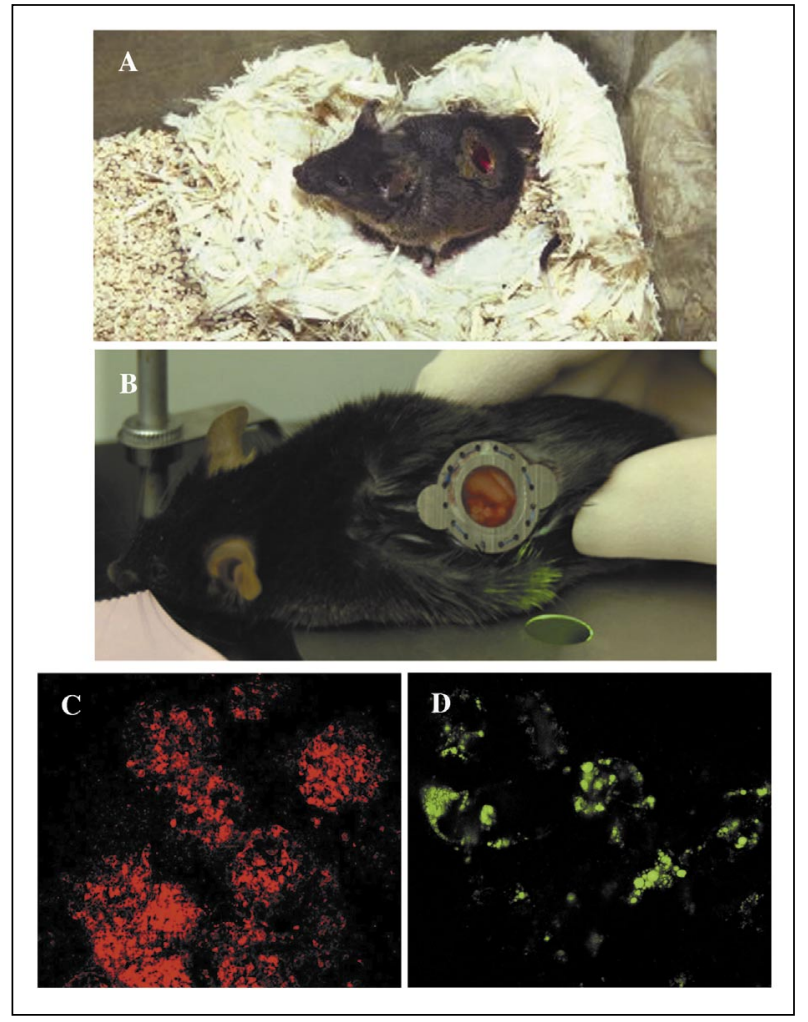

Figure 3. In vivo imaging through the body window. (A) Recipient animal $24 \mathrm{~h}$ after simultaneous islet transplantation and implantation of the body window. The mouse is alert and active. (B) Anesthetized animal being placed on the stage of the confocal microscope for imaging of the islet graft through the window. (C) In vivo image of the islet graft under the kidney capsule, which was taken through the window with a tetramethyl rhodamine isothiocyanate filter (red fluorescence). (D) In vivo image of $\mathrm{T}$ cells labeled with carboxy-fluorescein diacetate succinimidyl ester (CFSE; green fluorescence) that have migrated to the islet allograft site in an independent experiment. Magnification for panels $C$ and D was 40x. 
can move freely without expressing any sign of unease or distress (Figure $3 \mathrm{~A}$ ). For each imaging session, the animal is anesthetized and placed on the stage of the fluorescent microscope (Figure $3 \mathrm{~B})$. Figure $3 \mathrm{C}$ shows a picture of the engrafted Ins-C-Timer islets taken through the window, while Figure 3D shows independently labeled $\mathrm{T}$ cells. The body window may be kept in place until the animal heals completely (approximately two weeks), after which it can be removed without requiring that the animal be sacrificed.

The combination of Timer monitoring of insulin production with a body window holds much promise for future investigations that involve the tracking of $\mathrm{T}$ cells homing to the pancreas, insulin secretion under in vivo treatments, and islet behavior after transplantation.

The window technique, which is particularly well-suited for observing all the steps of an allorejection or its prevention in correctly immunosuppressed or tolerized animals, can also be implemented to study the animal's own endocrine pancreas to monitor the autoimmune process, provided that the site of the skin incision is appropriately positioned and the pancreas is in view through the window glass. These applications are currently being optimized. The same procedure would not only be valuable for diabetes research but could also be applied to any research that involves in vivo visualization over time.

The live-cell monitoring of Ins-CTimer stem cells will also facilitate the development of protocols leading to engineered $\beta$ cells that are fully functional for therapeutic approaches. In vivo multicolor imaging can be used to expand and differentiate Ins-C-Timer stem cells well beyond insulin-promoter activation to include physiologically relevant sustained secretory granule biogenesis and glucose-regulated exocytosis, with no need for immunohistological labeling, which is too frequently unreliable (15). The Ins-CTimer mouse can also be used as the bone marrow donor in the preparation of hematologically chimeric animals (16). The bone marrow transplant is sufficient to abolish the autoimmune process. Without autoimmunity, the regenerative properties of the endocrine pancreas can replace, over time, suf- ficient $\beta$ cells to guarantee euglycemia for an indefinite period of time, even in mice that are already diabetic (17). The question relative to the source of the regenerative process (i.e., bone marrow vs. pancreas) can be answered using these transgenic mice.

\section{ACKNOWLEDGMENTS}

This study was supported in part by the National Institutes of Health grant no. R01-DK06335-01 (to M.T., P.D., and S.C.W.), the Juvenile Diabetes Research Foundation Center grant no. 41999-845 (to M.T., R.B., A.N.B., P.D., and S.C.W.), and the Cochrane-Weber Endowed Fund in Diabetes Research (to S.B.).

\section{REFERENCES}

1.Bottino, R., A.N. Balamurugan, N. Giannoukakis, and M. Trucco. 2002. Islet/ pancreas transplantation: challenges for pediatrics. Pediatric Diabetes 3:210-223.

2.Shapiro, A.M.J., J.R.T. Lakey , E.A. Ryan, G.S. Korbutt, E. Toth, G.L. Warnock, N.M. Kneteman, and R.V. Rajotte. 2000. Islet transplantation in seven patients with type 1 diabetes mellitus using a glucocorticoid-free immunosuppressive regimen. N. Engl. J. Med. 343:230-238.

3.Ryan, E.A., J.R.T. Lakey, B.W. Paty, S. Imes, G.S. Korbutt, N.M. Kneteman, D. Bigam, R.V. Rajotte, et al. 2002. Successful islet transplantation. Diabetes 51:2148-2157.

4.Ryan, E.R., J.R. Lakey, B.W. Paty, G. Korbutt, N. Kneteman, D. Bigam, R.V. Rajotte, and J. Shapiro. 2002. Clinical follow-up after islet transplantation. Diabetes 51(Suppl 2):A32-33.

5.Terskikh, A., A. Fradkov, G. Ermakova, A. Zaraisky, P. Tan, A.V. Kajava, X. Zhao, S. Lukyanov, et al. 2000. "Fluorescent Timer": protein that changes color with time. Science 290:1585-1588.

6.Watkins, S., X. Geng, L. Li, G. Papworth, P.D. Robbins, and P. Drain. 2001. Imaging secretory vesicles by fluorescent protein insertion in propeptide rather than mature secreted peptide. Traffic 3:461-471.

7.Matz, M.V., A.F. Fradkov, Y.A. Labas, A.P. Savitsky, A.G. Zaraisky, M.L. Markelov, and S.A. Lukyanov. 1999. Fluorescent proteins from nonbioluminescent Anthozoa species. Nature 17:969-973.

8.Wentworth, B.M., I.M. Schaefer, L. Villa-Komaroff, and J.M. Chirgwin. 1986. Characterization of the two nonallelic genes encoding mouse preproinsulin. J. Mol. Evol. 23:305-312.

9.Hardy, S., M. Kitamura, T. Harris-Stansil, Y. Dai, and M.L. Phipps. 1997. Construction of adenovirus vectors through Cre-lox recom- bination. J. Virol. 71:1842-1849.

10.Alexander, A., M. Crawford, S. Bertera, W.A. Rudert, P.D. Robbins, and M. Trucco. 2002. Indoleamine 2,3-dioxygenase expression in transplanted NOD islets prolongs graft survival after adoptive transfer of diabetogenic splenocytes. Diabetes 51:356-365.

11.Bertera, S., M. Crawford, A. Alexander, G. Papworth, S.C. Watkins, P.D. Robbins, and M. Trucco. 2003. Gene transfer of manganese superoxide dismutase prolongs transplanted islet function in an autoimmune mouse model of diabetes. Diabetes 52:387-393.

12.Geng, X., L. Li, S. Watkins, P.D. Robbins, and P. Drain. 2003. The insulin secretory granule is the major site of KATP channels of the endocrine pancreas. Diabetes 52:767-776.

13.Pipeleers, D.G., M. Pipeleers-Marichal, J.C. Hannaert, M. Berghmans, P.A. In't Veld, J. Rozing, M. Van de Winkel, and W. Gepts. 1991. Transplantation of purified islet cells in diabetic rats. I. Standardization of islet cell grafts. Diabetes 40:908-919.

14.Tatarkiewicz, K., J. Hollister-Lock, R.R. Quickel, C.K. Colton, S. Bonner-Weir, and G.C. Weir. 1999. Reversal of hyperglycemia in mice after subcutaneous transplantation of macroencapsulated islets. Transplantation 67: 665-671.

15.Rajagopal, J., W.J. Anderson, S. Kume, O.I. Martinez, and D.A. Melton. 2003. Insulin staining of ES cell progeny from insulin uptake. Science 299:363.

16.Zorina, T.D., V.M. Subbotin, S. Bertera, A. Alexander, A.J. Styche, and M. Trucco. 2002. Distinct characteristics and features of allogeneic chimerism in the NOD mouse model of autoimmune diabetes. Cell Transplantation 11:113-123.

17.Zorina T.D., V.M. Subbotin, S. Bertera, A. Alexander, C. Haluszczak, A. Styche, B. Gambrell, R. Bottino, et al. 2003. Recovery of the endogenous beta cell function in the NOD model of autoimmune diabetes. Stem Cells 21:377-388.

Received 23 June 2003; accepted 15 July 2003.

Address correspondence to Massimo Trucco, Children's Hospital of Pittsburgh, Rangos Research Center, 3460 Fifth Avenue, Pittsburgh, Pennsylvania, 15213 USA. e-mail:mnt@pitt.edu 